\title{
Organ-specific autoimmunity in mice whose $T$ cell repertoire is shaped by a single antigenic peptide
}

\author{
Takamasa Oono, ${ }^{1}$ Yoshinori Fukui, ${ }^{1}$ Sadahiko Masuko, ${ }^{2}$ Osamu Hashimoto, ${ }^{3}$ \\ Takato Ueno, ${ }^{3}$ Terukazu Sanui, ${ }^{1}$ Ayumi Inayoshi, ${ }^{1}$ Mayuko Noda, ${ }^{1}$ Michio Sata, ${ }^{3}$ \\ and Takehiko Sasazuki ${ }^{1,4}$
}

\begin{abstract}
${ }^{1}$ Division of Immunogenetics, Department of Immunobiology and Neuroscience, Medical Institute of Bioregulation, and Core Research for Evolutional Science and Technology (CREST), Kyushu University, Fukuoka, Japan ${ }^{2}$ Department of Neuroanatomy, Saga Medical School, Saga, Japan

${ }^{3}$ Research Center for Innovative Cancer Therapy, Kurume University School of Medicine, Kurume, Japan

${ }^{4}$ International Medical Center of Japan, Tokyo, Japan
\end{abstract}

Address correspondence to: Takehiko Sasazuki, Division of Immunogenetics, Department of Immunobiology and Neuroscience, Medical Institute of Bioregulation, Kyushu University, 3-1-1 Maidashi, Higashi-ku, Fukuoka 812-8582, Japan. Phone: 81-92-642-6827; Fax: 81-92-632-0150; E-mail: sasazuki@bioreg.kyushu-u.ac.jp.

Takamasa Oono and Yoshinori Fukui contributed equally to this work.

Received for publication May 15, 2001, and accepted in revised form October 8, 2001.

\begin{abstract}
Organ-specific autoimmune diseases have been postulated to be the result of $\mathrm{T}$ cell response against organ-specific self-peptides bound to MHC molecules. Contrary to this paradigm, we report here that transgenic mice lacking MHC class I expression and expressing an MHC class II I-A $\mathrm{A}^{\mathrm{b}}$ molecule that presents only a single peptide (E $\alpha 52-68)$ spontaneously develops peripheral nervous system-specific autoimmune disease with many of the histopathological features found in experimental allergic neuritis. Reciprocal bone marrow chimeras produced using susceptible and resistant lines revealed that bone marrow-derived cells determined disease susceptibility. While the expression of the $\mathrm{I}-\mathrm{A}^{\mathrm{b}}-\mathrm{E} \alpha 52-68$ complex in the periphery was readily detectable in both lines, its expression on thymic dendritic cells responsible for tolerance induction was markedly lower in the susceptible line than in the resistant line. Consistent with this, $\mathrm{CD} 4^{+} \mathrm{T}$ cells that can be activated by the I- $\mathrm{A}^{\mathrm{b}}-\mathrm{E} \alpha 52-68$ complex were found in the susceptible line, but not in the resistant line. Such CD4 ${ }^{+}$ $T$ cells conferred the disease to the resistant line by adoptive transfer, and administration of $A b$ specific for the I-A $\mathrm{A}^{\mathrm{b}}-\mathrm{E} \alpha 52-68$ complex inhibited disease manifestation in the susceptible line. These results indicate that disease development involves systemic $T$ cell reactivity to I- $\mathrm{A}^{\mathrm{b}}-\mathrm{E} \alpha 52-68 \mathrm{com}-$ plex, probably caused by incomplete negative thymocyte selection.
\end{abstract}

J. Clin. Invest. 108:1589-1596 (2001). DOI:10.1172/JCI200113256.

\section{Introduction}

MHC class I and class II molecules are highly polymorphic glycoproteins that are expressed on the cell surface in association with self- or foreign antigenic peptides for recognition by $\mathrm{CD}^{+}$or $\mathrm{CD} 4^{+} \mathrm{T}$ cells, respectively (1). During development in the thymus, T cells are positively or negatively selected through the interaction of $\alpha \beta$ T cell receptors (TCRs) with self-peptides bound to self-MHC molecules. Positive selection rescues immature $\mathrm{T}$ cells from programmed cell death and ensures that mature $\mathrm{T}$ cell repertoire is directed against foreign peptides bound to self-MHC molecules (2-5), whereas negative selection plays a central role in tolerance induction by eliminating potentially self-reactive $T$ cells (6-9). Mature T cells, which survive these reciprocal selection processes and migrate to the periphery, respond to foreign peptides derived from bacteria, viruses, or parasites in association with self-MHC molecules expressed on antigen-presenting cells, and initiate immune response against invasion of such microorganisms. Thus, MHC molecules mediate two major immunological events, $\mathrm{T}$ cell repertoire selection in the thymus and immune response in the periphery, by presenting antigenic peptides to $\alpha \beta$ TCRs.

A predisposition to organ-specific autoimmune diseases is associated with particular alleles of MHC loci (10). Since MHC molecules affect immune responsiveness to foreign antigens by presenting distinct sets of peptides to T cells through polymorphism at the peptide-binding groove (11-15), it has been postulated that efficient binding of organ-specific self-peptides by disease-associated MHC molecules leads to T cell-mediated organ-specific autoimmunity (16-18). However, the recent findings of increased overall self-reactivity of $\mathrm{T}$ cells in spontaneous mouse models of organ-specific autoimmune diseases have cast some doubt on this paradigm (19-21). The $\mathrm{T}$ cells involved in autoimmune processes are selected to mature on disease-associated MHC molecules via positive and negative selection in the thymus. Therefore, it is possible that MHC association with organ-specific autoimmune diseases reflects a $T$ cell repertoire shaped by disease-associated MHC molecules bound to "unidentified" self-peptides in the thymus. However, this possibility has not been fully evaluated 
because of the difficulty in separately analyzing $\mathrm{T}$ cell repertoire selection and immune response in vivo.

Earlier, we reported on transgenic mouse lines that have been developed by introducing the gene encoding the I-A $\beta^{\mathrm{b}}$ chain covalently bound to $\mathrm{E} \alpha$ chain-derived peptide (E $\alpha 52-68)$ into mice lacking I-A $\beta^{\mathrm{b}}$, invariant chain, and $\beta 2$-microglobulin (TKO mice) (22-24). Thus far, no evidence has been provided that the I- $A^{b}$ molecules expressed in such mice present self- or foreign antigenic peptides other than E $\alpha 52-68$ to T cells $(22,25$, $26)$, suggesting that $\mathrm{I}-\mathrm{A}^{\mathrm{b}}-\mathrm{E} \alpha 52-68$ complex is the only MHC-peptide complex expressed in these mice. The expression of I-A $\mathrm{A}^{\mathrm{b}}-\mathrm{E} \alpha 52-68$ complex was readily detected in the thymic cortex and medulla in one mouse line, $\mathrm{B} 2 \mathrm{~L} \mathrm{TKO}$, whereas the expression in another line, H3 $\mathrm{TKO}$, was extremely low in the thymus $(22,24)$. However, $\mathrm{CD}^{+} \mathrm{T}$ cell differentiation was observed in both $\mathrm{B} 2 \mathrm{~L}$ TKO and H3 TKO mice $(22,24)$. Thus, these mice made it feasible to follow the immunological consequences of $\mathrm{CD}^{+} \mathrm{T}$ cells selected to mature on I-A $\mathrm{A}^{\mathrm{b}}-\mathrm{E} \alpha 52-68 \mathrm{com}-$ plex expressed at different levels in the thymus, without these $T$ cells being influenced by an immune response against other self- or foreign antigenic peptides.

Here we report the unexpected finding that H3 TKO mice spontaneously develop peripheral nervous system-specific autoimmune disease with many of the histopathological features found in experimental allergic neuritis, a model for Guillain-Barré syndrome (27, 28). By comparing H3 TKO mice with the resistant lines, B2L TKO mice and nontransgenic littermates (TKO mice), we demonstrate that disease development involves self-reactivity of $\mathrm{CD}^{+} \mathrm{T}$ cells to I-A ${ }^{\mathrm{b}}-\mathrm{E} \alpha 52-68$ complex, probably caused by its low expression on the thymic dendritic cells that are responsible for tolerance induction.

\section{Methods}

Mice. Three lines of transgenic mice that express the I-A $\beta^{\mathrm{b}}$ chain covalently bound to $E \alpha 52-68$ but lack endogenous $\mathrm{I}-\mathrm{A} \beta^{\mathrm{b}}$, invariant chain, and/or $\beta 2$-microglobulin have been described elsewhere (22-24). All mice were maintained under specific pathogen-free conditions, and mice hemizygous for the transgene were used in the present study. $A b s$. The following $\mathrm{mAbs}$ were purchased from PharMingen (San Diego, California, USA): FITCconjugated anti-CD8 (53-6.7), FITC-anti-CD45R (RA3-6B2), FITC-anti-CD62L (MEL-14), phycoerythrin-conjugated (PE-conjugated) anti-CD4 (RM4-5), PE-conjugated anti- $\alpha \beta$ TCR (H57-597), PE-antiNK1.1 (PK136), PE-anti-CD90.2 (53-2.1), biotinylated anti-CD11b (M1/70), biotinylated anti- $\gamma \delta$ TCR (GL3), biotinylated anti-CD44 (IM7), biotinylated anti-CD25 (7D4), and PE-anti-CD11c (HL3). YAe (an antibody against the I-A ${ }^{\mathrm{b}}-\mathrm{E} \alpha 52-68$ complex) (29) and Y3P (anti-I-A $)(30)$ were isolated from supernatants of the hybridoma cell cultures using a protein $\mathrm{G}$ column, and the biotinylated Abs were used in the staining experiments. The $\mathrm{mAb} 33 \mathrm{D} 1$, specific for splenic dendritic cells, was purchased from Leinco Technologies Inc. (St. Louis, Missouri, USA).
Toluidine blue staining and electron microscopy. Sciatic nerves were immersed in $2.5 \%$ glutaraldehyde in phosphate buffer for $14-16$ hours at $4{ }^{\circ} \mathrm{C}$, and postfixed in $1 \%$ osmium tetroxide supplemented with $1.5 \%$ potassium ferrocyanide in phosphate buffer for 2 hours at room temperature. Samples were dehydrated in a graded ethanol series. Semithin sections were stained with toluidine blue and examined by light microscopy. Ultrathin sections were stained with lead citrate and uranyl acetate, and examined using a JEOL 1200 EX electron microscope (Japan Electron Optics Laboratory, Tokyo, Japan).

Immunohistochemistry. Fresh-frozen tissue sections $(6 \mu \mathrm{m}$ thick) were prepared using a cryostat, and fixed in $100 \%$ acetone. Sections were stained with a panel of PE-conjugated $\mathrm{mAbs}$ in various combinations with biotinylated $\mathrm{mAbs}$ at $4^{\circ} \mathrm{C}$ for $14-16$ hours. They were then washed with PBS, and incubated with Oregon Green 488-conjugated streptavidin (Molecular Probes, Eugene, Oregon, USA) for 3 hours at room temperature. Sections were then rinsed in PBS and viewed with a fluorescence microscope (Nikon Corp., Tokyo, Japan). Fluorescence and phase-contrast images were taken using the HCC-3800, a 3-CCD color camera from Flovel Co. Ltd. (Tokyo, Japan). Images were processed using Adobe Photoshop 5.0 (Adobe Systems Inc., San Jose, California, USA). To assess infiltration of $\mathrm{CD}_{11 \mathrm{~b}^{+}}$macrophages into sciatic nerves, frozen sections were first incubated with biotinylated anti-CD11b $\mathrm{mAb}$, then reacted with peroxidase-avidin. Sections were visualized in a fresh mixture of $0.02 \% 3,3^{\prime}$-diaminobenzidine in Tris-HCl buffer (0.005 M, pH 7.6).

Cell preparation and flow cytometry. Splenic and thymic dendritic cells were prepared from spleens or thymi that were treated with collagenase D (Roche Molecular Biochemicals, Indianapolis, Indiana, USA), then centrifuged in dense BSA to provide a low-density population, and stained with YAe in combination with FITC-33D1 or FITC-anti-CD8 and PE-anti-CD11c $\mathrm{mAbs}$, respectively. The expression of $\mathrm{I}-\mathrm{A}^{\mathrm{b}}-\mathrm{E} \alpha 52-68$ complex on splenic B cells was assessed by staining spleen cells with FITC-anti-CD45R mAb and biotinylated YAe followed by streptavidin-PE. The cell-surface expression of CD44, CD62L, or CD25 on $\mathrm{CD} 4^{+} \mathrm{T}$ cells was analyzed by staining spleen cells with the relevant Abs. Analyses were done on a FACScan flow cytometer using CellQuest software (Becton Dickinson Immunocytometry Systems, San Jose, California, USA).

$\mathrm{CD}^{+} \mathrm{T}$ cell proliferation and cytokine production. Splenic $\mathrm{CD}^{+} \mathrm{T}$ cells were prepared from disease-affected $\mathrm{H} 3$ TKO mice using Dynabeads M-450 coated with antimouse CD4 mAb and DETACHaBEAD (both from Dynal Biotech, Oslo, Norway). These cells were cultured with irradiated B2H TKO spleen cells in the presence of $10 \%$ T-STIM culture supplement without ConA (Collaborative Biomedical Products, Bedford, Massachusetts, USA). After three or four rounds of stimulation, viable cells $\left(1 \times 10^{5} /\right.$ well $)$ recovered using Lympholyte-M (Cedarlane Laboratories Ltd., Hornby, Ontario, Canada) were cultured with irradiated spleen cells $\left(1 \times 10^{6} /\right.$ well $)$ from B2H TKO mice or TKO mice 
for 80 hours in the presence or absence of YAe at 20 $\mu \mathrm{g} / \mathrm{ml}$. During the final 16 hours of culture, $1 \mu \mathrm{Ci}$ of $\left[{ }^{3} \mathrm{H}\right]$ thymidine was added, and the incorporated radioactivity was measured. In some experiments, the production of IL-2, IL-4, or IFN- $\gamma$ was measured using the Biotrak ELISA system (Amersham Pharmacia Biotech, Buckinghamshire, United Kingdom).

Bone marrow chimeras and adoptive transfer. After eliminating mature $\mathrm{T}$ and $\mathrm{B}$ cells, bone marrow cells prepared from $\mathrm{H} 3 \mathrm{TKO}$ or B2L TKO mice were transferred into irradiated (850 cGy) B2L TKO, H3 TKO, or TKO mice $\left(1 \times 10^{7}\right.$ cells/recipient mouse). In some experiments, $\mathrm{CD}^{+}$ peripheral lymph node cells $\left(5-8 \times 10^{6}\right)$ from the affected $\mathrm{H} 3 \mathrm{TKO}$ mice were stimulated with $\mathrm{B} 2 \mathrm{H}$ TKO spleen cells in the presence of anti-CD3 $\mathrm{mAb}(1 \mu \mathrm{g} / \mathrm{ml})$ and $10 \%$ T-STIM culture supplement without ConA, and transferred into the recipient mice at the time of reconstitution. $A b$ administration. One milligram of YAe or the isotypematched Ab BB7.2, specific for HLA-A2, was intraperitoneally administered to $\mathrm{H} 3 \mathrm{TKO}$ or $\mathrm{B} 2 \mathrm{H}$ TKO mice every 3-4 days, starting when mice were 7 weeks old. Sciatic nerves were prepared from $\mathrm{H} 3 \mathrm{TKO}$ mice at the age of 16 weeks and analyzed for infiltration of CD11 $\mathrm{b}^{+}$ macrophages. For B2H TKO mice, the proportion of splenic B cells or dendritic cells expressing I-A ${ }^{b}-E \alpha 52-68$ complex was analyzed with flow cytometry.

\section{Results}

During the course of breeding, we found that $\mathrm{H} 3 \mathrm{TKO}$ mice exhibited dysfunction of their hind limbs. At 10 weeks old or later, they showed atony or clasping of hind limbs when lifted by the tail, and this dysfunction progressed gradually, with marked muscle atrophy. Thirty-three of fifty H3 TKO mice (66\%) developed dysfunction of hind limbs and muscle atrophy by the age of 20 weeks. There was no significant difference in incidence between males and females $(71.0 \%$ and $57.9 \%$, respectively). In contrast, these clinical symptoms were not observed in B2L TKO mice or TKO mice. To visualize the pathological processes underlying the clinical manifestations of disease, we performed histological analysis. Each hind limb muscle from the affected H3 TKO mice was less than $60 \%$, by weight, of that of nontransgenic littermates. The neuromuscular junctions did not show noticeable abnormalities in histology (data not shown). However, while compact myelinated axons were observed in the sciatic nerves of TKO and B2L TKO mice (Figure 1, a and b), the sciatic nerves from affected $\mathrm{H} 3 \mathrm{TKO}$ mice showed demyelination and axon degeneration with massive cell infiltration, especially around the blood vessels (Figure 1c). This became more evident with electron microscopic analysis, which showed that degenerated myelin was phagocytosed by
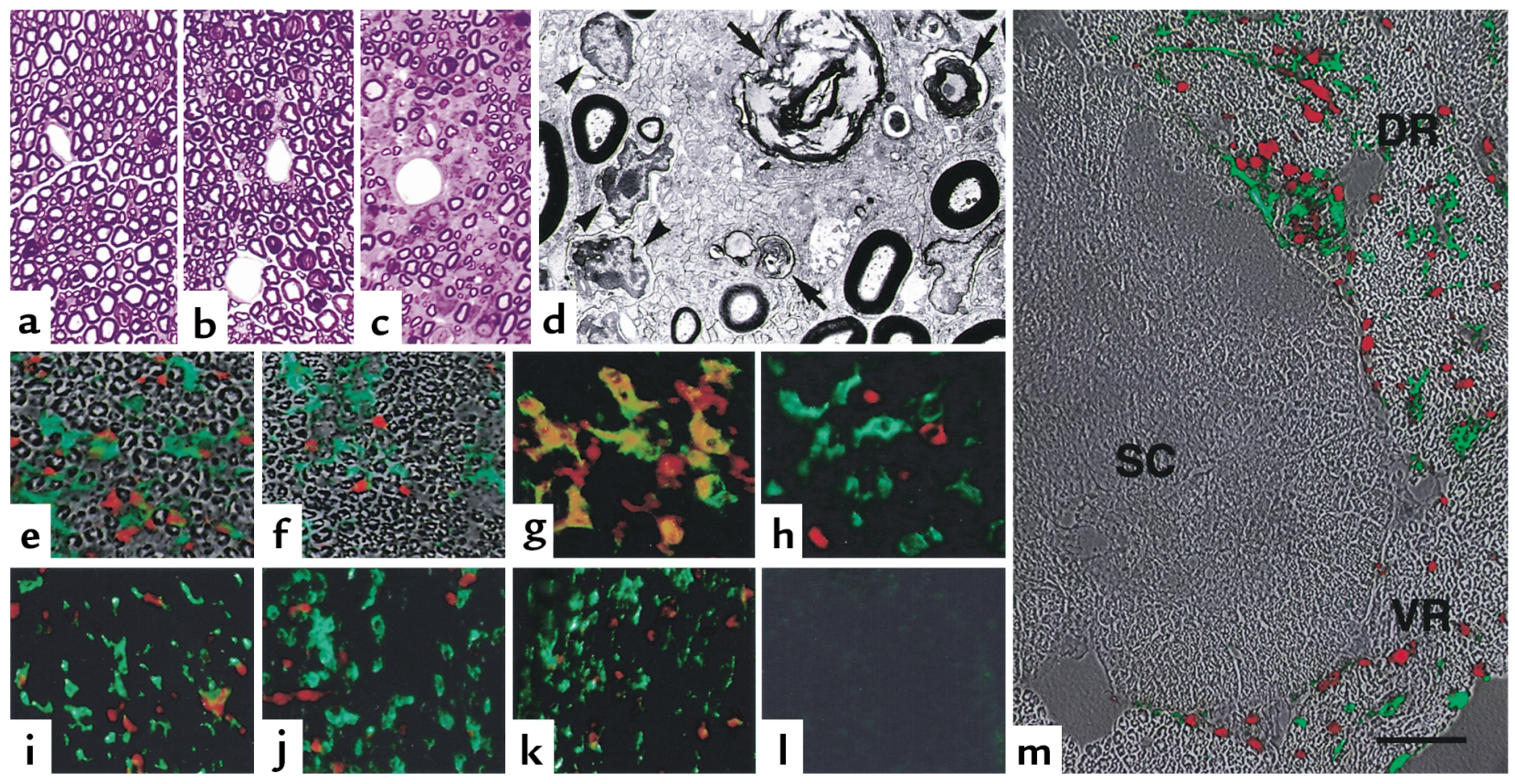

Figure 1

Histopathology of the peripheral nervous system in affected H3 TKO mice. (a-c) The sciatic nerves from TKO (a), B2L TKO (b), and disease-affected H3 TKO mice (c) were stained with toluidine blue. (d) Electron micrograph of the same H3 TKO sciatic nerve shown in c, showing accumulation of lymphoid cells (arrowheads) around macrophages containing degenerated myelin sheaths within phagosomes (arrows). (e-h) Double immunofluorescence histochemistry of the sciatic nerve from an affected H3 TKO mouse shows infiltration of many CD11 b cells (e and $\mathbf{f}$, green) and $\mathrm{CD} 4^{+}$cells $\left(\mathbf{e}\right.$, red), and small numbers of NK1. $1^{+}$cells $(\mathbf{f}$, red). Immunoreactivity for CD4 ( $\mathbf{g}$ and $\mathbf{h}$, green) is colocalized with that for $\alpha \beta$ TCR (g, red), but not with that for NK1.1 (h, red). (i-m) The presence or absence of CD11 b macrophages (green) and CD4 ${ }^{+} \mathrm{T}$ cells (red) in the facial (i), trigeminal (j), vagus (k), and optic (I) nerves, and in the spinal cord (SC), and dorsal (DR) and ventral (VR) roots of the spinal nerve ( $\mathbf{m})$ of affected H3 TKO mice. All peripheral nerve types sustain massive infiltration of CD4+ $4^{+}$cells and CD11 $b^{+}$macrophages (i-k and $\mathbf{m}, \mathrm{DR}$ and VR), whereas the central nervous tissues are intact $(\mathbf{I}$ and $\mathbf{m}, \mathrm{SC})$. Each fluorescence image is superimposed on the phase-contact image of the same field (e, f, and $\mathbf{m})$. The scale bar represents $40 \mu \mathrm{m}$ in $\mathbf{a}-\mathbf{c}, 5 \mu \mathrm{m}$ in $\mathbf{d}, 50 \mu \mathrm{m}$ in $\mathbf{e}, \mathbf{f}$, and $\mathbf{i}-\mathbf{l}, 25 \mu \mathrm{m}$ in $\mathbf{g}$ and $\mathbf{h}$, and $80 \mu \mathrm{m}$ in $\mathbf{m}$. 
Histological analysis of the sciatic nerves from various mouse strains

\begin{tabular}{|c|c|c|c|c|c|c|c|}
\hline \multirow[b]{2}{*}{ Strain } & \multirow[b]{2}{*}{ Time of analysis } & \multirow[b]{2}{*}{ Treatment } & \multicolumn{4}{|c|}{ Histological grade ${ }^{A}$} & \multirow[b]{2}{*}{ Score ${ }^{B}$} \\
\hline & & & $(-)$ & $(+)$ & $(++)$ & $(+++)$ & \\
\hline $\mathrm{H} 3 \mathrm{TKO}(n=23)$ & 20 weeks of age, or within 1 week of onset of clinical symptoms & $(-)$ & 1 & 4 & 5 & 13 & 2.30 \\
\hline $\mathrm{B} 2 \mathrm{LTKO}(n=11)$ & 20 weeks of age & $(-)$ & 10 & 1 & 0 & 0 & 0.09 \\
\hline TKO $(n=13)$ & 20 weeks of age & $(-)$ & 11 & 2 & 0 & 0 & 0.15 \\
\hline $\mathrm{H} 3 \mathrm{TKO}(n=5)$ & 7 weeks of age & $(-)$ & 5 & 0 & 0 & 0 & 0.00 \\
\hline $\mathrm{H} 3 \rightarrow \mathrm{B} 2 \mathrm{~L}$ chimera $(n=6)$ & 14 weeks after reconstitution & $(-)$ & 1 & 1 & 0 & 4 & 2.17 \\
\hline $\mathrm{H} 3 \rightarrow \mathrm{TKO}$ chimera $(n=5)$ & 14 weeks after reconstitution & $(-)$ & 5 & 0 & 0 & 0 & 0.00 \\
\hline $\mathrm{B} 2 \mathrm{~L} \rightarrow \mathrm{H} 3$ chimera $(n=6)$ & 14 weeks after reconstitution & $(-)$ & 5 & 1 & 0 & 0 & 0.17 \\
\hline $\mathrm{B} 2 \mathrm{~L} \rightarrow \mathrm{H} 3$ chimera $(n=5)$ & $10-13$ weeks after reconstitution & 3 TKO CD $4+$ T cells & 0 & 1 & 1 & 3 & 2.40 \\
\hline $\mathrm{H} 3 \mathrm{TKO}(n=7)$ & 16 weeks of age & YAe & 5 & 1 & 1 & 0 & 0.43 \\
\hline H3 TKO $(n=7)$ & 16 weeks of age & Control Ab & 2 & 1 & 0 & 4 & 1.86 \\
\hline
\end{tabular}

AThe extent of $\mathrm{CD} 11 \mathrm{~b}^{+}$cell infiltration in sciatic nerve sections was used to judge the histological grade: $(-)$no cell infiltration; $(+)<1 / 3 ;(++) 1 / 3-2 / 3$; $(+++)>2 / 3$. The analysis was done by blinded pathologists. BValues were calculated as follows: $[\Sigma$ (histological grade) $\times($ the number of mice observed with each grade) $] /$ (the number of analyzed mice).

macrophage-like cells rich in organelles, around which lymphoid cells gathered (Figure 1d). Immunohistochemical analysis revealed that the cells infiltrating the sciatic nerve of the affected H3 TKO mice expressed either CD4, CD11b, or NK1.1 (Figure 1, e and f). While $\mathrm{CD}^{+}$infiltrating cells also expressed $\alpha \beta$ TCRs (Figure $1 \mathrm{~g}$ ), these cells were not stained with the mAb specific for NK1.1 (Figure 1h). Cells expressing CD8, $\gamma \delta$ TCR, or CD45R were scarcely detected among the infiltrating cells (data not shown). Taken together, these results indicate that the sciatic nerves are infiltrated primarily by $\mathrm{CD}^{+} \alpha \beta \mathrm{TCR}^{+} \mathrm{T}$ cells and macrophages.

To assess organ specificity, we extended this analysis to other peripheral and central nerves as well as other organs of the affected H3 TKO mice. Although demyelination and axon degeneration were less severe in some peripheral nerves than in the sciatic nerve, infiltration of $\mathrm{CD}^{+} \mathrm{T}$ cells and macrophages was observed in the facial nerve, the trigeminal nerve, the vagus nerve, and the dorsal and ventral roots of the spinal nerve (Figure $1, \mathrm{i}-\mathrm{k}$ and $\mathrm{m}$ ), indicating that the peripheral nervous system, irrespective of nerve location and function, is affected in $\mathrm{H} 3 \mathrm{TKO}$ mice. In contrast, the optic nerve, the spinal cord, and other organs including brain, liver, pancreas, kidney, and salivary glands, did not show any cell infiltration (Figure 1, 1 and $\mathrm{m}$, and data not shown). These results indicate that the peripheral nervous system is strictly distinguished from other nerves and organs, and is specifically attacked in $\mathrm{H} 3 \mathrm{TKO}$ mice.

When the sciatic nerves of H3 TKO mice were analyzed within a week of clinical onset of symptoms, or at 20 weeks old in the case of the lack of clinical manifestations of disease, infiltration of $\mathrm{CD}_{11} \mathrm{~b}^{+}$macrophages was observed in almost all cases (Table 1). In contrast, the sciatic nerves of $\mathrm{H} 3 \mathrm{TKO}$ mice analyzed at 7 weeks old, and those of B2L TKO or TKO mice analyzed at 20 weeks old, did not show such cell infiltration (Table 1). Interestingly, however, while disease development was not observed with TKO mice that had been irradiated and reconstituted with $\mathrm{H} 3 \mathrm{TKO}$ bone marrow cells $(\mathrm{H} 3 \rightarrow$ TKO chimera), B2L TKO mice similarly reconstituted with $\mathrm{H} 3 \mathrm{TKO}$ bone marrow cells $(\mathrm{H} 3 \rightarrow \mathrm{B} 2 \mathrm{~L}$ chimera) developed peripheral neuritis that was clinically and histopathologically equivalent to that seen in H3 TKO mice (Table 1). On the other hand, we found that reconstitution with B2L TKO bone marrow cells prevented H3 TKO mice from developing the disease (B2L $\rightarrow \mathrm{H} 3$ chimera, Table 1). These results indicate that, in addition to thymic epithelial cells expressing I-A $\mathrm{A}^{\mathrm{b}}-\mathrm{E} \alpha 52-68$ complex, bone marrow-derived cells from H3 TKO mice are required for disease development.

H3 TKO and B2L TKO mice differed markedly in expression levels of I-A ${ }^{\mathrm{b}}-\mathrm{E} \alpha 52-68$ complex in the thymic medulla (Figure 2a), where potentially self-reactive $\mathrm{T}$ cells are eliminated primarily through interaction with thymic dendritic cells (31-33). Having found that bone marrow-derived cells determine disease susceptibility, we compared the expression of I-A ${ }^{\mathrm{b}}-\mathrm{E} \alpha 52-68$ complex on thymic dendritic cells in $\mathrm{H} 3 \mathrm{TKO}$ and B2L TKO mice. Expression of I-A $\mathrm{A}^{\mathrm{b}}-\mathrm{E} \alpha 52-68$ complex was markedly lower on thymic dendritic cells of H3 TKO mice than on those of B2L TKO mice (Figure 2b). However, expression of I-A $A^{b}-E \alpha 52-68$ complex was readily detected on splenic $B$ cells and dendritic cells in both B2L TKO and H3 TKO mice (Figure 2, c and d).

This raised the possibility that low expression of I-Ab-E $\alpha 52-68$ complex on H3 TKO thymic dendritic cells results in incomplete negative selection and contributes to the disease development. To address this issue, we first compared immunological tolerance of $\mathrm{CD}^{+} \mathrm{T}$ cells to I-A ${ }^{\mathrm{b}}-\mathrm{E} \alpha 52-68$ complex in H3 TKO and B2L TKO mice. The proportion of splenic $\mathrm{CD} 4^{+} \mathrm{T}$ cells was $7.0 \% \pm 1.2 \%$ in $\mathrm{H} 3 \mathrm{TKO}$ mice, whereas that in TKO and B2L TKO mice was $3.4 \% \pm 0.5 \%$ and $11.5 \% \pm 0.9 \%$, respectively. While the expression of $\mathrm{CD} 44$ and $\mathrm{CD} 62 \mathrm{~L}$ on splenic $\mathrm{CD} 4^{+} \mathrm{T}$ cells from H3 TKO mice was intermediate between that in TKO and B2L TKO mice (Figure $3 \mathrm{a}$ ), the proportion of $\mathrm{CD}^{+}{ }^{+} \mathrm{CD} 25^{+} \mathrm{T}$ cells to total splenic $\mathrm{CD} 4^{+} \mathrm{T}$ cells in $\mathrm{H} 3$ TKO mice was markedly higher than that in TKO or B2L TKO mice (Figure $3 b$ ). In primary culture, splenic $\mathrm{CD}^{+}$ $\mathrm{T}$ cells from H3 TKO mice did not show any detectable proliferative response to I- $\mathrm{A}^{\mathrm{b}}-\mathrm{E} \alpha 52-68$ complex. This was the case even when the cells were stimulated with $\mathrm{B} 2 \mathrm{H}$ TKO spleen cells expressing this complex as a single 
species at the highest level among the three lines (22) (data not shown). However, after three or four rounds of stimulation with B2H TKO spleen cells in the presence of cytokines, splenic $\mathrm{CD}^{+} \mathrm{T}$ cells from $\mathrm{H} 3 \mathrm{TKO}$ mice, but not those from B2L TKO mice, showed a definite proliferative response to B2H TKO spleen cells (Figure 3c). This response was not observed with TKO spleen cells and was blocked by the mAb YAe, which is specific for I-A - E $\alpha 52-68$ complex (29). When $\mathrm{CD}^{+}{ }^{+} \mathrm{T}$ cells from $\mathrm{H} 3$ TKO mice were stimulated with $\mathrm{B} 2 \mathrm{H}$ TKO spleen cells, these cells produced IFN- $\gamma$ and IL-4 (Figure 3d), but not IL-2 (data not shown). These results indicate that the peripheral $\mathrm{T}$ cell repertoire of $\mathrm{H} 3 \mathrm{TKO}$ mice, but not $\mathrm{B} 2 \mathrm{~L}$ TKO mice, includes self-reactive $\mathrm{CD}^{+}{ }^{+} \mathrm{T}$ cells that can be

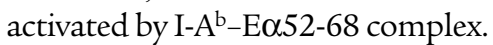

We then explored the question of whether development of peripheral neuritis is mediated by $\mathrm{CD} 4^{+} \mathrm{T}$ cells in adoptive transfer experiments. For this purpose, we prepared $\mathrm{CD}^{+} \mathrm{T}$ cells from peripheral lymph nodes of $\mathrm{H} 3 \mathrm{TKO}$ mice that were afflicted with peripheral neuritis, and expanded the $\mathrm{CD} 4^{+} \mathrm{T}$ cells by stimulating them with $\mathrm{B} 2 \mathrm{H}$ TKO spleen cells in the presence of anti-CD3 $\mathrm{mAb}$ and cytokines. While the sciatic nerves of $\mathrm{B} 2 \mathrm{~L} \rightarrow \mathrm{H} 3$ chimera mice did not show any cell infiltration (Table 1), inoculation with $\mathrm{CD}^{+} \mathrm{T}$ cells from H3 TKO mice affected with peripheral neuritis, together with B2L TKO bone marrow cells, resulted in infiltration of $\mathrm{CD}^{+} \mathrm{T}$ cells and $\mathrm{CD} 11 \mathrm{~b}^{+}$macrophages in all cases (Table 1 and Figure 4). These results indicate that a $\mathrm{CD}^{+} \mathrm{T}$ cell-mediated immunological process is involved in development of peripheral neuritis.

In $\mathrm{H} 3 \mathrm{TKO}$ mice, MHC class II I-A ${ }^{\mathrm{b}}$ molecules, which serve as ligands for TCRs expressed on $\mathrm{CD}^{+} \mathrm{T}$ cells, form complexes with E $\alpha 52-68$. To investigate whether peripheral neuritis involves self-reactivity to the I-A $A^{\mathrm{b}}-\mathrm{E} \alpha 52-68$ complex, we administered $1 \mathrm{mg}$ of the mAb YAe to H3 TKO mice every 3-4 days, starting at the age of 7 weeks. While four of seven H3 TKO mice similarly treated with the isotype-matched control $\mathrm{Ab}$ developed peripheral neuritis by the age of 16 weeks, none of those treated with YAe exhibited clinical manifestations of disease. When the sciatic nerves were analyzed for $\mathrm{CD} 11 \mathrm{~b}^{+}$cell infiltration at 16 weeks of age, YAe administration was found to markedly improve the histological score (Table 1). It is clear that the suppressive effect of YAe on disease development does not result from elimination of antigen-presenting cells, because the proportions of dendritic cells and $\mathrm{B}$ cells expressing I-A ${ }^{\mathrm{b}}-\mathrm{E} \alpha 52-68$ complex in the spleen were not changed much by YAe treatment (Figure 5).

This finding led us to closely examine the expression of I-A ${ }^{b}-E \alpha 52-68$ complex using two mAbs: YAe, which is specific for I-A $\mathrm{A}^{\mathrm{b}} \mathrm{E} \alpha 52-68$ complex (29), and Y3P, which reacts with $\mathrm{I}-\mathrm{A}^{\mathrm{b}}$ molecules irrespective of the binding peptide (30). While no expression of I-A ${ }^{\mathrm{b}}-\mathrm{E} \alpha 52-68$ complex was detected in muscle, liver, pancreas, or kidney (data not shown), both YAe and Y3P strongly stained the vascular endothelium of the sciatic nerves of $\mathrm{H} 3 \mathrm{TKO}$ mice afflicted with peripheral neuritis (Figure 6, a and b). Since
I- $\mathrm{A}^{\mathrm{b}}$ molecules that were stained with Y3P, but not with YAe, were not found in the serial sections, it seems that $\mathrm{I}-\mathrm{A}^{\mathrm{b}}$ molecules on the vascular endothelium are occupied with E $\alpha 52-68$ at this level of detection. This is similar to the situation with antigen-presenting cells $(22,25,26)$. When the spinal nerve was analyzed, strong expression of I-A $A^{b}-E \alpha 52-68$ complex was observed on the vascular endothelium of the dorsal and ventral roots. The complex was not found on vascular endothelium of the spinal cord (Figure 6c). Similar results were obtained with $\mathrm{B} 2 \mathrm{~L} \rightarrow \mathrm{H} 3$ chimeras inoculated with $\mathrm{H} 3 \mathrm{TKO} \mathrm{CD}^{+} \mathrm{T}$ cells (Figure 6d). On the other hand, the expression of $\mathrm{I}-\mathrm{A}^{\mathrm{b}}-\mathrm{E} \alpha 52-68$ complex was not detected in the peripheral nervous tissues from 7-week-old H3 TKO mice or 20-week-old B2L TKO mice, in which no cell infiltration was detected (data not shown). However, we found that sciatic nerve sections from $\mathrm{H} 3 \rightarrow \mathrm{B} 2 \mathrm{~L}$ chimera did not express I- $\mathrm{A}^{\mathrm{b}}-\mathrm{E} \alpha 52-68$ complex on the vascular endothelium, despite infiltration of $\mathrm{CD}^{+} \mathrm{T}$ cells (Figure 6e).

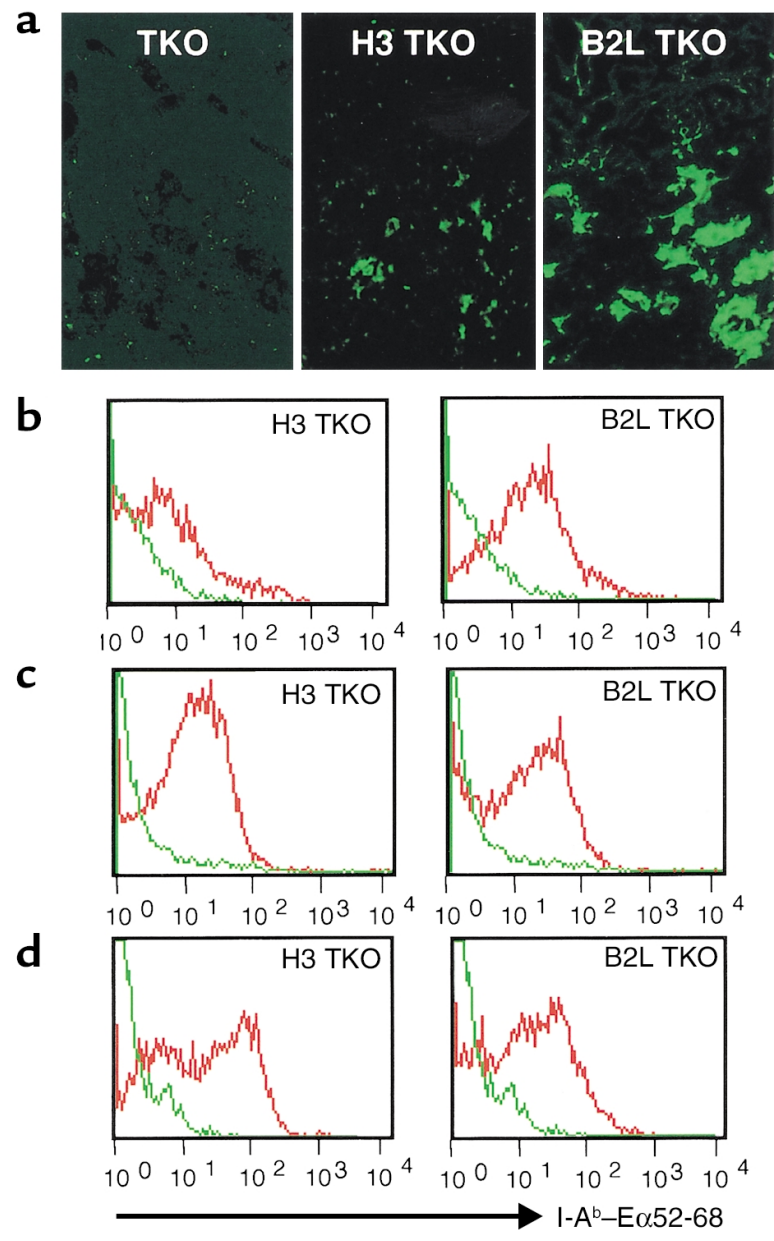

\section{Figure 2}

The expression of I-A $-\mathrm{b} \alpha 52-68$ complex on bone marrow-derived cells in the thymus and periphery. Thymus sections from TKO, H3 TKO, and B2L TKO mice were stained with YAe (a). The expression levels of

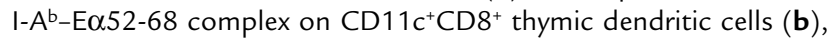
CD45R $\mathrm{R}^{+}$splenic $\mathrm{B}$ cells $(\mathbf{c})$, and $33 \mathrm{D} 1^{+}$splenic dendritic cells $(\mathbf{d})$ were compared in $\mathrm{H} 3 \mathrm{TKO}$ and $\mathrm{B} 2 \mathrm{~L}$ TKO mice. The profiles of $\mathrm{B} 2 \mathrm{LTKO}$ and $\mathrm{H} 3 \mathrm{TKO}$ mice (red) are shown with that of TKO mice (green). 
a

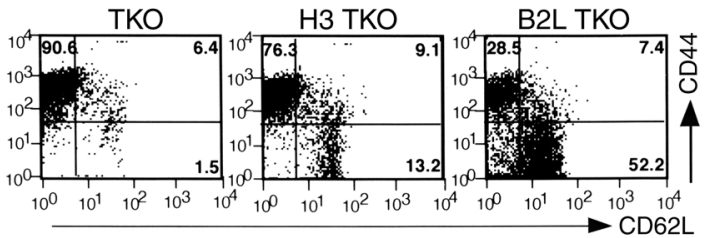

b
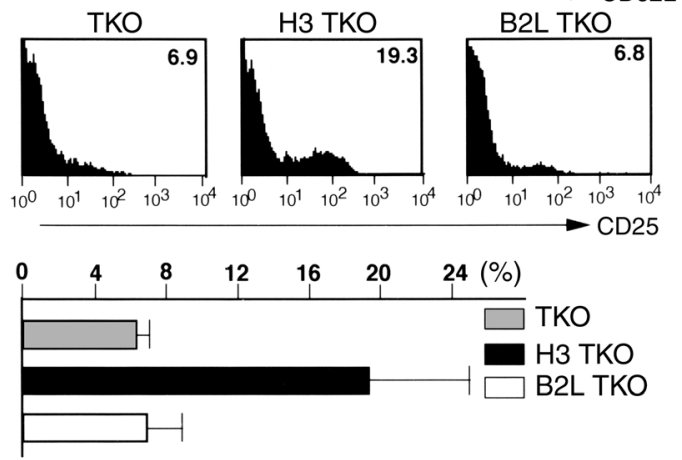

c

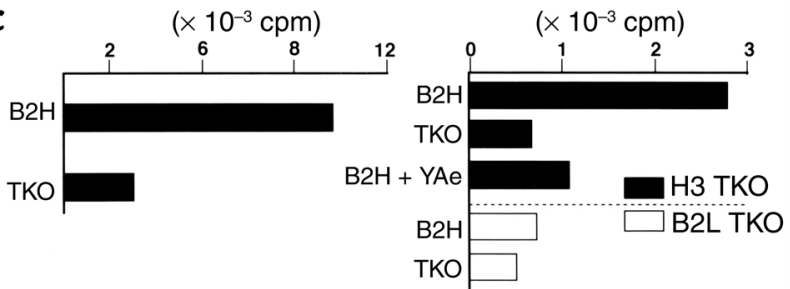

d

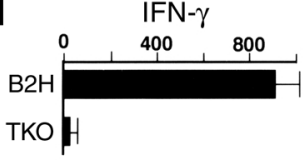

\section{Discussion}

In the present study, we have shown that a transgenic mouse line, H3 TKO, which expresses I- $\mathrm{A}^{\mathrm{b}}$ molecule covalently bound to E $\alpha 52-68$ as its only MHC-peptide complex, spontaneously develops a demyelinating peripheral neuritis with infiltration of numerous $\mathrm{CD}^{+} \alpha \beta \mathrm{TCR}^{+} \mathrm{T}$ cells and macrophages. Such neuritis was not observed in TKO and B2L TKO mice. However, reconstitution with $\mathrm{H} 3 \mathrm{TKO}$ bone marrow cells conferred the disease to B2L TKO mice, but not to TKO mice, suggesting that $\mathrm{CD}^{+} \mathrm{T}$ cells selected to mature on I-A - E $252-68$ complex are required for disease development. This was shown more directly by another finding: while peripheral neuritis did not develop in $\mathrm{B} 2 \mathrm{~L} \rightarrow \mathrm{H} 3$ chimeras, inoculation of $\mathrm{CD}^{+}{ }^{+} \mathrm{T}$ cells from affected $\mathrm{H} 3$ TKO lymph nodes induced a similar pathological change in this line. These results suggest that the peripheral neuritis observed in $\mathrm{H} 3 \mathrm{TKO}$ mice results from $\mathrm{CD}^{+} \mathrm{T}$ cell-mediated autoimmunity, rather than being a result of transgene position or an undetected infection.

The disease-susceptible line, H3 TKO, was originally developed in a double-knockout genetic background that lacks I- $A \beta^{\mathrm{b}}$ and invariant chains, but expresses endogenous MHC class I molecules H3 DKO (22); we had never seen development of peripheral neuritis in this background (data not shown). Lack of the disease development in $\mathrm{H} 3 \mathrm{DKO}$ mice might be the result of immune regulation in the periphery by $\mathrm{CD}^{+} \mathrm{T}$ cells or

\section{Figure 3}

Phenotypic and functional analysis for self-reactivity of $\mathrm{CD} 4^{+} \mathrm{T}$ cells in $\mathrm{H} 3 \mathrm{TKO}$ mice. (a) Expression of CD62L and CD44 on splenic CD4 ${ }^{+}$ T cells from TKO, H3 TKO, and B2L TKO mice. The proportions of $\mathrm{CD}_{2} \mathrm{~L}^{+} \mathrm{CD} 44^{-}, \mathrm{CD} 62 \mathrm{~L}^{+} \mathrm{CD} 44^{+}$, and $\mathrm{CD} 62 \mathrm{~L}^{-} \mathrm{CD} 44^{+}$cells are indicated. (b) Expression of CD25 on splenic CD4 ${ }^{+} \mathrm{T}$ cells from TKO, H3 TKO, and B2L TKO mice (upper panels), and comparison of proportions of $\mathrm{CD} 4{ }^{+} \mathrm{CD} 25^{+}$splenic T cells in these three lines (lower panel). TKO, $n=4$; H3 TKO, $n=7$; B2L TKO, $n=4$. (c and d) After three or four rounds of stimulation of splenic $\mathrm{CD}^{+} T$ cells from $\mathrm{H} 3$ TKO (filled bars) or B2L TKO (open bars) mice with irradiated B2H TKO spleen cells in the presence of cytokines, viable cells $\left(1 \times 10^{5} /\right.$ well $)$ were cultured with irradiated spleen cells $\left(1 \times 10^{6} /\right.$ well $)$ from B2H TKO or TKO mice in the presence or absence of YAe $(20 \mu \mathrm{g} / \mathrm{ml})$. The results represent the mean of $\left[{ }^{3} \mathrm{H}\right]$ thymidine incorporation of duplicate cultures (c), and mean and SD of cytokine production of triplicate cultures (d). For the experiments shown in $\mathbf{c}$ and $\mathbf{d}$, three independent short-term-cultured $\mathrm{CD} 4^{+} \mathrm{T}$ cell lines were prepared from diseaseaffected $\mathrm{H} 3 \mathrm{TKO}$ mice. B2H, B2H TKO.

$\mathrm{CD} 4^{+} \mathrm{NK} 1.1^{+}$natural killer T cells (NKT cells), the development of which requires classical or nonclassical MHC class I molecules $(34,35)$; or it could be due to elimination of the pathogenic $\mathrm{CD} 4^{+} \mathrm{T}$ cells by MHC class I molecules in the thymus. Alternatively, MHC class I expression might suppress self-reactivity of $\mathrm{CD}^{+} \mathrm{T}$ cells by simply increasing the number of $\mathrm{T}$ cells, because it has been reported that reducing the total size of the T cell pool causes native $T$ cells to become overtly reactive to positively selecting peptide ligands $(36,37)$. Although the mechanism for disease inhibition by endogenous MHC class I expression awaits further study, this also argues against the involvement of a position effect of the transgene in disease development.

Immune responsiveness is determined by MHC molecules through $\mathrm{T}$ cell repertoire selection in the thymus and antigen presentation in the periphery. However, since MHC class I expression is lacking and MHC class II I-A ${ }^{\mathrm{b}}$

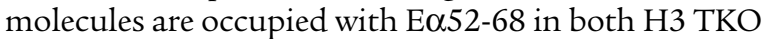
and B2L TKO mice, it is likely that the differential susceptibility of these lines to autoimmune disease is attributable to $\mathrm{T}$ cell repertoire selection directed by I-A $A^{b}-E \alpha 52-68$ complex that is expressed in the thymus at different levels. Reciprocal bone marrow chimeras of
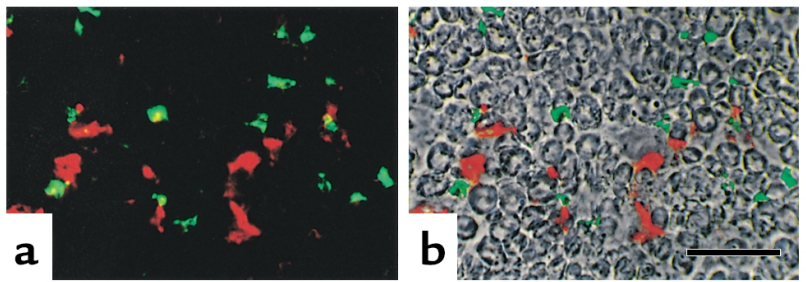

\section{Figure 4}

Adoptive transfer of $\mathrm{CD}^{+}$lymph node cells from disease-affected $\mathrm{H} 3$ TKO mice causes peripheral neuritis. Activated peripheral lymph node $\mathrm{CD}^{+} \mathrm{T}$ cells from affected $\mathrm{H} 3 \mathrm{TKO}$ mice were transferred into irradiated, 7-week-old H3 TKO mice, along with B2L TKO bone marrow cells. Sciatic nerve sections were prepared and stained for CD11b (green) and CD4 (red) at 10-13 weeks after the transfer. A double immunofluorescence image (a) is superimposed on the phase-contrast image of the same field (b). The scale bar represents $40 \mu \mathrm{m}$. 


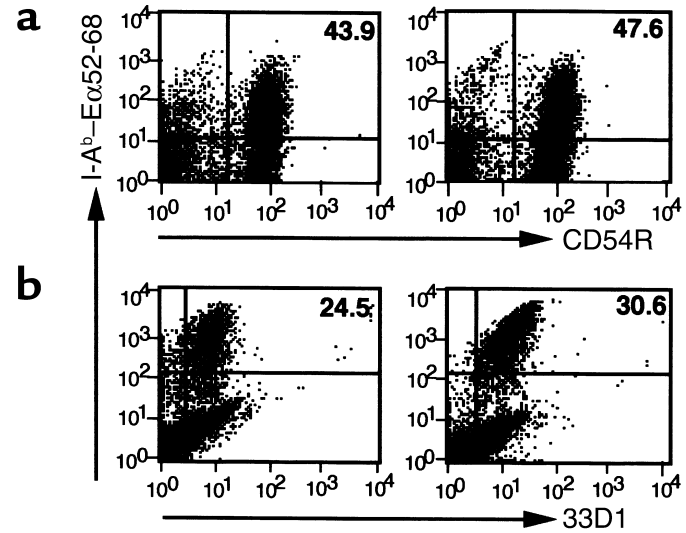

Figure 5

Comparison of $B$ cells and dendritic cells expressing I-A $A^{b}-E \alpha 52-68$ complex before and after YAe treatment. Spleen cells (a) and dendritic cell-enriched fractions (b) were prepared from B2H TKO mice with (left) or without (right) YAe treatment, and stained with YAe and anti-CD45R $\mathrm{mAb}$ (for detection of $\mathrm{B}$ cells) or 33D1 (for detection of splenic dendritic cells). The proportions of splenic $B$ cells and dendritic cells expressing $\mathrm{I}-\mathrm{A}^{\mathrm{b}}-\mathrm{E} \alpha 52-68$ complex are indicated in upper right hand corners.

$\mathrm{H} 3 \mathrm{TKO}$ and $\mathrm{B} 2 \mathrm{~L}$ TKO mice revealed that bone marrow-derived cells from $\mathrm{H} 3 \mathrm{TKO}$ mice are critical for disease development. While the expression of I- $\mathrm{A}^{\mathrm{b}}-\mathrm{E} \alpha 52-68$ complex in the peripheral antigen presenting cells of $\mathrm{H} 3$ TKO mice was comparable to or somewhat higher than that expression in B2L TKO mice, its expression on the thymic dendritic cells responsible for tolerance induction was markedly lower in $\mathrm{H} 3 \mathrm{TKO}$ mice than in B2L TKO mice. Consistent with this, the mature $\mathrm{T}$ cell repertoire of $\mathrm{H} 3 \mathrm{TKO}$ mice, but not of B2L TKO mice, included CD4 ${ }^{+}$ $\mathrm{T}$ cells that were reactive to I- $\mathrm{A}^{\mathrm{b}}-\mathrm{E} \alpha 52-68$ complex. We have also shown that administration of YAe inhibits manifestation of the autoimmune disease without eliminating antigen-presenting cells. Taken together, these results strongly suggest that incomplete negative selection directed by low-expressing of I-A $\mathrm{A}^{\mathrm{b}}-\mathrm{E} \alpha 52-68$ complex in the thymus, and the resultant "leakiness" of self-reactivity to this selecting ligand, are involved in disease development. At this stage, however, it remains unclear how self-reactive $\mathrm{CD} 4^{+} \mathrm{T}$ cells are activated in the periphery, and how such activation leads to organ-specific autoimmune disease in $\mathrm{H} 3 \mathrm{TKO}$ mice. It may be that the activation of self-reactive $\mathrm{CD} 4^{+} \mathrm{T}$ cells is a result of the

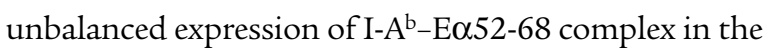
thymus and periphery in this line; that is, extremely low expression on thymic dendritic cells and relatively high expression on peripheral antigen-presenting cells.

Ridgeway et al. reported that immunological tolerance of $\mathrm{T}$ cells to several self-peptides, irrespective of organ specificity, is insufficient in nonobese diabetic (NOD) mice, a model for type I diabetes, and suggested that this can be attributed to negative selection directed by I-Ag7 $(20,21)$. A more convincing case for involvement of incomplete negative selection in organ-specific autoimmune diseases was made by Kouskoff et al., who showed that the transgenic KRN mouse line, expressing $\alpha \beta$ TCR with cross-reactivity to $\mathrm{I}^{\mathrm{Ag}} \mathrm{g}^{7}$, developed joint-specific autoimmune disease when crossed with mice expressing

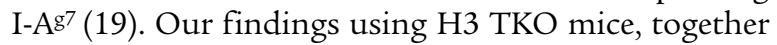
with results from studies of NOD and KRN mice, raise the possibility that many of the spontaneous organ-specific autoimmune diseases are provoked by systemic selfreactivity of $T$ cells - reactivity that is generated through $\mathrm{T}$ cell repertoire selection that is directed by disease-associated MHC molecules in the thymus. The present study suggests that $\mathrm{T}$ cell repertoire selection directed by low expressioning MHC-self-peptide complex causes such systemic $T$ cell self-reactivity. A similar situation might occur with $\mathrm{T}$ cells selected by unstable MHC-self-peptide complexes. Regarding these possibilities, it is interesting to note that I-A ${ }^{87}$, which determines susceptibility to the autoimmune diseases in NOD and KRN mice, has been reported as a poor or promiscuous peptide binder that may lack high-affinity binding peptides $(38,39)$.

The results from $\mathrm{H} 3 \mathrm{TKO}$ and $\mathrm{KRN}$ mice resemble each other in that these mice, which have limited diversity of TCR ligands or TCRs, spontaneously develop

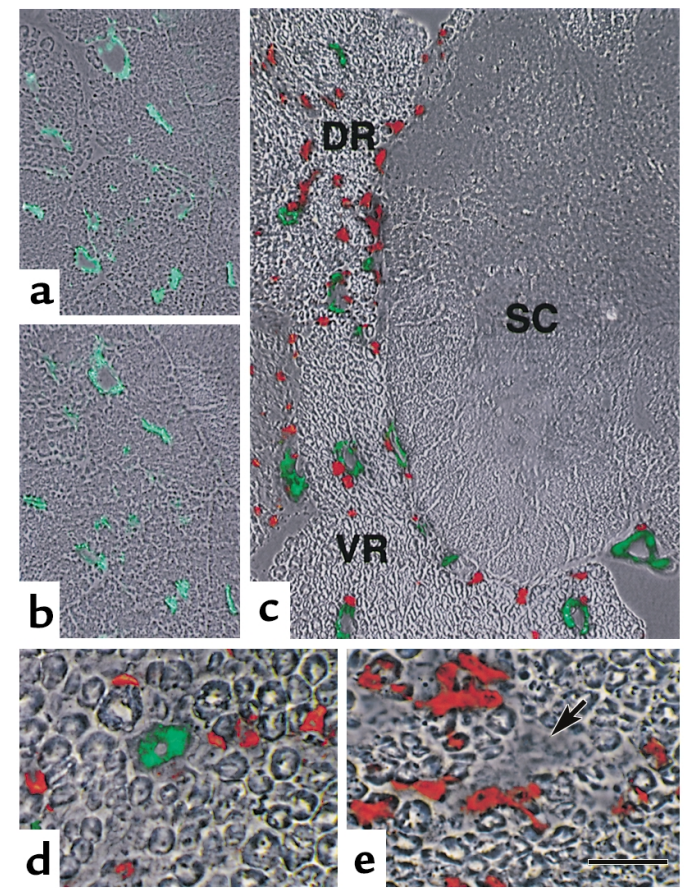

\section{Figure 6}

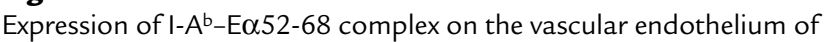
peripheral nerves from disease-affected H3 TKO mice. ( $\mathbf{a}$ and $\mathbf{b}$ ) Serial sciatic nerve sections from affected $\mathrm{H} 3$ TKO mice with peripheral neuritis were stained with $\mathrm{YAe}$ (a, green) and $\mathrm{Y} 3 \mathrm{P}$ (b, green). (c) Fresh-frozen sections from affected $\mathrm{H} 3$ TKO mice including the dorsal and ventral roots of the spinal nerve (DR and VR) and the spinal cord (SC) were stained with $\mathrm{YAe}$ (green) and anti-CD4 mAb (red). (d) Sciatic nerve sections from $\mathrm{B} 2 \mathrm{~L} \rightarrow \mathrm{H} 3$ chimeras inoculated with $\mathrm{H} 3 \mathrm{TKO} \mathrm{CD}^{+} \mathrm{T}$ cells were stained with $\mathrm{YAe}$ (green) and anti-CD4 mAb (red). (e) Sciatic nerve sections from $\mathrm{H} 3 \rightarrow \mathrm{B} 2 \mathrm{~L}$ chimeras were stained with $\mathrm{YAe}$ (green) and anti-CD4 mAb (red). The l- $A^{b}-E \alpha 52-68$ complex is not expressed in the vascular walls (arrow). Each fluorescence image was superimposed on the phase-contrast image of the same field (a-e). The scale bar represents $100 \mu \mathrm{m}$ in $\mathbf{a}$ and $\mathbf{b}, 80 \mu \mathrm{m}$ in $\mathbf{c}$, and $25 \mu \mathrm{m}$ in $\mathbf{d}$ and $\mathbf{e}$. 
organ-specific autoimmune disease as a consequence of the systemic self-reactivity of $\mathrm{CD}^{+} \mathrm{T}$ cells. However, the processes leading to organ-specific autoimmunity are different in these two models. Disease onset in KRN is acute (19), whereas H3 TKO mice take a chronic course. Joint-specific autoimmune disease in KRN mice was shown to involve humoral response to a ubiquitously expressed self-antigen, glucose-6-phosphate isomerase $(40,41)$. However, serum from H3 TKO mice with peripheral neuritis could neither stain sciatic nerve sections nor transfer the disease (data not shown). On the other hand, we found that I-A $\mathrm{A}^{\mathrm{b}}-\mathrm{E} \alpha 52-68$ complex was strongly expressed on the vascular endothelium of the peripheral nervous system of the affected mice. Since sciatic nerve sections from $\mathrm{H} 3 \rightarrow \mathrm{B} 2 \mathrm{~L}$ chimera showed cell infiltration without expression of I-A ${ }^{\mathrm{b}}-\mathrm{E} \alpha 52-68$ complex on the vascular endothelium, it seems likely that such expression is the result of inflammation in nearby parenchymal tissue, rather than being the cause of the disease. Nonetheless, it is conceivable that I-A ${ }^{\mathrm{b}}-\mathrm{E} \alpha 52-68$ complex expressed on the vascular endothelium could be involved in disease manifestation by facilitating the entry of self-reactive $\mathrm{CD} 4^{+} \mathrm{T}$ cells into the tissue and/or inducing cytokine secretion by them.

In conclusion, we have provided a novel mouse model for organ-specific autoimmune diseases in which peripheral nervous tissues are specifically attacked as a consequence of systemic self-reactivity of $\mathrm{CD} 4^{+} \mathrm{T}$ cells. Our findings suggest that the expression level of MHC-self-peptide complexes in the thymus, especially on thymic dendritic cells, contributes to susceptibility to organ-specific autoimmune disease by determining the size and affinity of the self-reactive $\mathrm{T}$ cell repertoire.

\section{Acknowledgments}

We thank D.B. Murphy and M. Kimoto for providing us with the $\mathrm{B}$ cell hybridomas YAe and $\mathrm{Y} 3 \mathrm{P}$, respectively. This work was supported by grants from the Ministry of Education, Culture, Sports, Science and Technology of Japan, and from the Japan Science and Technology Corporation.

1. Germain, R.N. 1994. MHC-dependent antigen processing and peptide presentation. Cell. 76:287-299.

2. Kisielow, P., Teh, H.S., Blüthman, H., and von Boehmer, H. 1988. Positive selection of antigen-specific T cells in thymus by restricting MHC molecules. Nature. 335:730-733.

3. Sha, W.C., et al. 1988. Selective expression of an antigen receptor on CD8bearing T lymphocytes in transgenic mice. Nature. 335:271-274.

4. Teh, H.-S., et al. 1988. Thymic major histocompatibility complex antigens and the $\alpha \beta$ T-cell receptor determine the CD4/CD8 phenotype of T cells. Nature. 335:119-233.

5. Berg, L.J., et al. 1989. Antigen/MHC-specific T cells are preferentially exported from the thymus in the presence of their MHC ligand. Cell. 58:1035-1046.

6. Kappler, J.W., Roehm, N., and Marrack, P. 1987. T cell tolerance by clonal elimination in the thymus. Cell. 49:273-280.

7. MacDonald, H.R., et al. 1988. T-cell receptor $V \beta$ use predicts reactivity and tolerance to Mlsa-encoded antigens. Nature. 332:40-45.

8. Kisielow, P., Blüthman, H., Staerz, U.D., Steinmetz, M., and von Boehmer, H. 1988. Tolerance in T-cell-receptor transgenic mice involves deletion of nonmature $\mathrm{CD}^{+} 8^{+}$thymocytes. Nature. 333:742-746.

9. Murphy, K.M., Heimberger, A.B., and Loh, D.Y. 1990. Induction by antigen of intrathymic apoptosis of $\mathrm{CD}^{+}{ }^{+} \mathrm{CD}^{+}{ }^{+} \mathrm{TCR}^{\text {lo }}$ thymocytes in vivo. Science. 250:1720-1723.

10. Todd, J.A., et al. 1988. A molecular basis for MHC class II-associated autoimmunity. Science. 240:1003-1009.

11. Benacerraf, B., and McDevitt, H.O. 1972. Histocompatibility-linked immune response genes. Science. 175:273-279.

12. Babbitt, B.P., Allen, P.M., Matsueda, G., Haber, E., and Unanue, E.R. 1985. Binding of immunogenetic peptides to Ia histocompatibility molecules. Nature. 317:359-361.

13. Sette, A., et al. 1987. Structural characteristics of an antigen required for its interaction with Ia and recognition by T cells. Nature. 328:395-399.

14. Guillet, J.-G., et al. 1987. Immunological self, nonself discrimination. Science. 235:865-870.

15. Rammensee, H.-G., Friede, T., and Stevanovic, S. 1995. MHC ligands and peptide motifs: first listing. Immunogenetics. 41:178-228.

16. Todd, J.A., Bell, J.I., and McDevitt, H.O. 1987. HLA-DQ $\beta$ gene contributes to susceptibility and resistance to insulin-dependent diabetes mellitus. Nature. 329:599-604.

17. Sinha, A.A., Lopez, M.T., and McDevitt, H.O. 1990. Autoimmune diseases: the failure of self-tolerance. Science. 248:1380-1388.

18. Theofilopoulos, A.N. 1995. The basis of autoimmunity: part I. Mechanisms of aberrant self-recognition. Immunol. Today. 16:90-98.

19. Kouskoff, V., et al. 1996. Organ-specific disease provoked by systemic autoimmunity. Cell. 87:811-822.

20. Ridgeway, W.M., Fassó, M., Lanctot, A., Garvey, C., and Fathman, C.G. 1996. Breaking self-tolerance in nonobese diabetic mice. J. Exp. Med. 183:1657-1662.

21. Ridgeway, W.M., Ito, H., Fassó, M., Yu, C., and Fathman, C.G. 1998. Analysis of the role of the variation of major histocompatibility complex class II expression on nonobese diabetic (NOD) peripheral T cell response. J. Exp. Med. 188:2267-2275.

22. Fukui, Y., et al. 1997. Positive and negative CD4 $4^{+}$thymocyte selection by a single MHC class II/peptide ligand affected by its expression level in the thymus. Immunity. 6:401-410.

23. Fukui, Y., et al. 1998. Highly restricted T cell repertoire shaped by a single major histocompatibility complex-peptide ligand in the presence of a single rearranged T cell receptor $\beta$ chain. J. Exp. Med. 188:897-907.

24. Fukui, Y., et al. 2000. Diversity of T cell repertoire shaped by a single peptide ligand is critically affected by its amino acid residue at a $T$ cell receptor contact. Proc. Natl. Acad. Sci. USA. 97:13760-13765.

25. Ignatowicz, L., Kappler, J., and Marrack, P. 1996. The repertoire of T cells shaped by a single MHC/peptide ligand. Cell. 84:521-529.

26. Grubin, C.E., Kovats, S., deRoos, P., and Rudensky, A.Y. 1997. Deficient positive selection of CD4 $\mathrm{T}$ cells in mice displaying altered repertoires of $\mathrm{MHC}$ class II-bound self-peptides. Immunity. 7:197-208.

27. Waksman, B.H., and Adams, R.D. 1955. Allergic neuritis: an experimental disease of rabbits by the injection of peripheral nervous tissue and adjuvants. J. Exp. Med. 102:213-236.

28. Hahn, A.F. 1996. Experimental allergic neuritis (EAN) as a model for the immune-mediated demyelinating neuropathies. Rev. Neurol. 5:328-332.

29. Rudensky, A., Rath, S., Preston-Hurburt, P., Murphy, D., and Janeway, C.A., Jr. 1991. On the complexity of the self. Nature. 353:660-662.

30. Janeway, C.A., Conrad, P., Lerner, E., Babich, J., and Wettstein, P. 1984. Monoclonal antibodies specific for Ia glycoproteins raised by immunization with activated T cells: possible role of T cell-bound Ia antigens as targets of immunoregulatory T cells. J. Immunol. 132:662-669.

31. Marrack, P., et al. 1988. The effect of thymus environment on T cell development and tolerance. Cell. 53:627-634.

32. Sprent, J., Lo, D., Gao, E.-K., and Ron, Y. 1988. T cell selection in the thymus. Immunol. Rev. 101:173-189.

33. Laufer, T.M., Dekoning, J., Markowitz, J.S., Lo, D., and Glimcher, L.H. 1996. Unopposed positive selection and autoreactivity in mice expressing class II MHC on thymic cortex. Nature. 383:81-85.

34. Bendelac, A., Killeen, N., Littman, D.R., and Schwartz, R.H. 1994. A subset of $\mathrm{CD}^{+}$thymocytes selected by MHC class I molecules. Science. 263:1774-1778.

35. Bendelac, A., et al. 1995. CD1 recognition by mouse NK1 $1^{+}$thymocytes. Science. 268:863-865

36. Ernst, B., Lee, D.-P., Chang, J.M., Sprent, J., and Surh, C.D. 1999. The peptide ligands mediating positive selection in the thymus control $\mathrm{T}$ cell survival and homeostatic proliferation in the periphery. Immunity. 11:173-181.

37. Goldrath, A.W., and Bevan, M.J. 1999. Low-affinity ligands for the TCR drive proliferation of mature $\mathrm{CD}^{+} \mathrm{T}$ cells in lymphopenic hosts. Immunity. 11:183-190.

38. Carrasco-Martin, E., Shimizu, J., Kanagawa, O., and Unanue, E.R. 1996. The class II MHC I-A $\mathrm{A}^{7}$ molecules from non-obese diabetic mice are poor peptide binders. J. Immunol. 156:450-458.

39. Stratmann, T., et al. 2000. The I-Ag7 MHC class II molecule linked to murine diabetes is a promiscuous peptide binder. J. Immunol. 165:3214-3225.

40. Korganow, A.-S., et al. 1999. From systemic T cell self-reactivity to organspecific autoimmune disease via immunoglobulins. Immunity. 10:451-461.

41. Matsumoto, I., Staub, A., Benoist, C., and Mathis, D. 1999. Arthritis provoked by linked T and B cell recognition of a glycolytic enzyme. Science. 286:1732-1735 